\title{
Pneumocystis carinii pneumonia in vertically acquired HIV infection in the British Isles
}

\author{
D M Gibb, C F Davison, F J Holland, S Walters, V Novelli, J Mok
}

Department of

Epidemiology and

Biostatistics, Division

of Public Health,

Institute of Child

Health, London

D M Gibb

C F Davison

F J Holland

Department of

Paediatrics, St Mary's

Hospital, London

$S$ Walters

Hospital for Sick Children, London V Novelli

City Hospital, Edinburgh

J Mok

Correspondence to Dr D M Gibb, Epidemiology and Biostatistics Unit, Institute of Child Health, 30 Guilford Street, London WCIN 1EH.

Accepted 29 October 1993

Table 1 AIDS indicator diseases ${ }^{\star}$ in children with AIDS born in the British Isles

\begin{tabular}{|c|c|c|c|c|}
\hline & \multicolumn{2}{|c|}{$\begin{array}{l}\text { Present at AIDS } \\
\text { diagnosis }\end{array}$} & \multirow{2}{*}{$\begin{array}{l}\text { Onset } \\
\text { after AIDS } \\
\text { diagnosis }\end{array}$} & \multirow[b]{2}{*}{$\begin{array}{l}\text { Median (range) } \\
\text { age (months) }\end{array}$} \\
\hline & Alone & $\begin{array}{l}\text { With } \\
\text { others }\end{array}$ & & \\
\hline \multicolumn{5}{|l|}{ Opportunistic infections } \\
\hline P carinii pneumonia & 11 & 11 & 2 & $4 \cdot 1(1 \cdot 4-27 \cdot 3)$ \\
\hline Disseminated cytomegalovirus & 0 & 6 & 0 & $3 \cdot 5(2 \cdot 2-5 \cdot 5)$ \\
\hline Cryptosporidiosis & 2 & 0 & 1 & $52.9(16.7-53.4)$ \\
\hline Oesophageal candidiasis & 0 & 0 & 3 & $40 \cdot 6(9 \cdot 9-61 \cdot 9)$ \\
\hline Atypical mycobacterium & 0 & 0 & 0 & - \\
\hline Extrapulmonary tuberculosis & 0 & 0 & 1 & $57 \cdot 4$ \\
\hline $\begin{array}{l}\text { Toxoplasmosis, herpes simplex, } \\
\text { coccidiomycosis }\end{array}$ & 0 & 0 & 0 & S14 \\
\hline Failure to thrivet & 4 & 14 & 3 & $8 \cdot 1(3 \cdot 4-77 \cdot 2)$ \\
\hline Recurrent bacterial infection & 5 & 6 & 9 & $20 \cdot 2(5 \cdot 6-77 \cdot 2)$ \\
\hline Encephalopathy $\ddagger$ & 3 & 4 & 7 & $15 \cdot 5(0 \cdot 3-72 \cdot 3)$ \\
\hline \multicolumn{5}{|l|}{ Neoplasms } \\
\hline Lymphoma & 1 & 0 & 1 & $29.9(26.0-33.8)$ \\
\hline Kaposi's sarcoma & 0 & 0 & 0 & - \\
\hline \multicolumn{5}{|l|}{ Lymphoid interstitial pneumonitis $\Omega$} \\
\hline Mild or asymptomatic & 7 & 3 & 1 & $16 \cdot 0(2 \cdot 8-56 \cdot 5)$ \\
\hline Severe & 0 & 2 & 0 & $15 \cdot 1(9 \cdot 0-21 \cdot 3)$ \\
\hline Total No of AIDS indicator diseases & 33 & 46 & 28 & \\
\hline Total No of children & 33 & 22 & 13 & \\
\hline
\end{tabular}

^Some cases had multiple diagnoses.

†Crossing two weight for age centiles $(97,90,75,50,25,10,3)$.

$¥$ Two or more of: acquired microcephaly, loss of milestones, progressive motor deficits; all over a period of at least three months.

§Severe: respiratory failure, oxygen dependence, exercise intolerance with oxygen intolerance. Mild: chest radiograph without respiratory signs or symptoms.
Children with HIV infection develop $P$ carinii pneumonia at an early age and have a poor outcome. Increased awareness of the condition is required to initiate early treatment. Prevention may be a compelling incentive for screening in pregnancy, but further study is required to quantify the risks and benefits of initiating early $P$ carinii pneumonia prophylaxis as well as the impact this might have on life expectancy.

(Arch Dis Child 1994; 70: 241-244)

The clinical spectrum and outcome of AIDS in children with vertically acquired infection with HIV type I has been well described in a number of hospital based cohorts. ${ }^{12}$ Pneumocystis carinii pneumonia has been identified as the most common and serious AIDS indicator disease. ${ }^{34}$ However, most of these studies were based on the experience of a single centre which may have an unrepresentative referral pattern. Paediatric HIV surveillance in the British Isles (United Kingdom and Republic of Ireland) includes reports of children born to seropositive women as well as children presenting with symptomatic HIV disease. ${ }^{5}$ This paper describes the clinical course, laboratory findings, and outcome for children with HIV infection who developed $P$ carinii pneumonia.

\section{Methods}

In the British Isles, active surveillance of pregnant women and children with HIV infection is carried out through two confidential reporting schemes. HIV positive pregnant women are reported through the Royal College of Obstetricians and Gynaecologists and paediatricians report HIV seropositive children through an active monthly reporting scheme at the British Paediatric Surveillance Unit (BPSU). Details of the two linked schemes, which have been operating since 1989 and have over $90 \%$ response rates, have been reported previously. ${ }^{5}$ Each report is followed up using a standard questionnaire. Clinical data collected on infected children include details and dates of AIDS indicator diseases, other HIV related signs and symptoms, antiretroviral treatment, prophylaxis, and $\mathrm{T}$ cell subsets. The definitions of AIDS and HIV related manifestations are printed on the back of the questionnaire and follow the definition of the Centers for Disease Control in Atlanta with modifications to the definitions of failure to thrive, encephalopathy, and lymphocytic interstitial pneumonitis (see table 1). Reports 

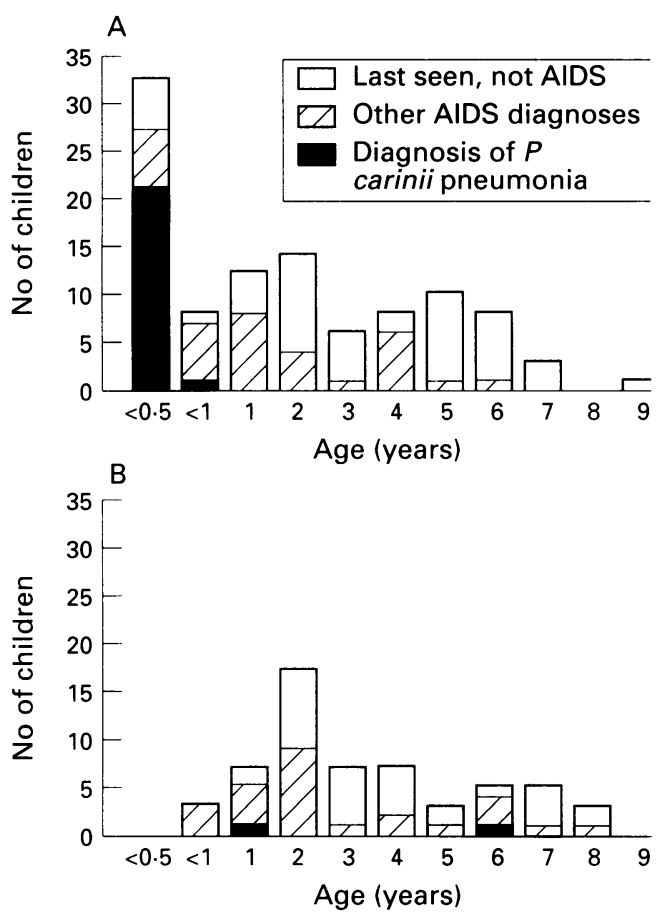

Figure 1 Details of $160^{\star}$ children with vertically acquired HIV infection - ages at AIDS diagnosis or age last seen but not yet AIDS. (A) born in the British Isles: 55 AIDS, 48 other infected and (B) born abroad: 27 AIDS, 30 other infected. ${ }^{\star}$ In nine children the country of birth and clinical data were not available.

are followed up annually to monitor clinical progression, age at onset of AIDS, and age at death. Paediatricians are requested to report if a child develops AIDS or dies in the interim.

Further details on the clinical illness in children reported with $P$ carinii pneumonia were sought from the paediatricians using a standard questionnaire, maintaining confidentiality. Data were collected on the presenting illness, method of diagnosis, treatment, use of ventilation, and outcome of the illness. These data were combined with data collected through the surveillance scheme.

Table $2 \mathrm{P}$ carinii pneumonia in children born in the British Isles: clinical manifestations

\begin{tabular}{|c|c|c|c|}
\hline & \multicolumn{2}{|c|}{ HIV risk first ascertained } & \multirow[b]{2}{*}{ Total } \\
\hline & $\begin{array}{l}\text { Befor P carinii } \\
\text { pneumoniu illness }\end{array}$ & $\begin{array}{l}\text { After P carinii } \\
\text { pneumonia illness }\end{array}$ & \\
\hline No of children & 8 & 16 & 24 \\
\hline \multicolumn{4}{|l|}{ Race } \\
\hline White & 6 & 7 & 13 \\
\hline Black or mixed & 2 & 9 & 11 \\
\hline $\begin{array}{l}\text { Median (range) age at } P \text { carinii } \\
\text { pneumonia onset (months) }\end{array}$ & Median (range) age at $P$ carinii & $4 \cdot 3(2 \cdot 0-8 \cdot 3)$ & $4 \cdot 1(1 \cdot 4-27 \cdot 4)$ \\
\hline $\begin{array}{l}\text { Interval between onset of symptoms } \\
\text { and starting treatment (days) }\end{array}$ & $13(3-49)$ & $11^{\star}(2-42)$ & $11(2-49)$ \\
\hline \multicolumn{4}{|l|}{$\begin{array}{l}\text { No }(\%) \text { with } P \text { carinii pneumonia } \\
\text { diagnosis: }\end{array}$} \\
\hline Presumptive & 2 & 4 & $6(25)$ \\
\hline Definitive & 6 & 12 & $18(75)$ \\
\hline Nasopharyngeal aspirate & 3 & 8 & \\
\hline Bronchoalveolar lavage & 2 & 1 & \\
\hline Lung biopsy & 0 & 2 & \\
\hline At postmortem examination & 1 & 1 & \\
\hline No $(\%)$ ventilated & $2(25)$ & $12(75)$ & $14(58)$ \\
\hline $\begin{array}{l}\text { No (\%) died of } P \text { carinii pneumonia } \\
\text { illness }\end{array}$ & $5(63)$ & $10(63)$ & $15(63)$ \\
\hline No $(\%)$ survived to three months & $3(38)$ & $6(38)$ & $9(38)$ \\
\hline
\end{tabular}

^In one child information was not available.

\section{Results}

By October 1992, 169 children with vertically acquired HIV infection had been reported. Eighty two had developed AIDS, of whom 40 had died. Figure 1 shows the age at AIDS diagnosis or the age last seen for children without an AIDS diagnosis. Further details of the AIDS indicator diseases occurring in those children born in the British Isles are shown in table 1 .

Twenty seven children were initially reported to have $P$ carinii pneumonia. However, after questionnaires on the clinical details were returned, the diagnosis had been revised in three children. In two of these children, a confirmed diagnosis of cytomegalovirus and adenoviral pneumonia respectively had been made, and in the third, it was not possible to obtain any information about the diagnosis, but the child is alive and well, with a high CD4 count at age 5 years.

Among the 55 children with AIDS born in the British Isles, $P$ carinii pneumonia was observed only in infancy and occurred in 22 $(40 \%)$ at AIDS diagnosis; among the 27 born abroad, only two $(7 \%)$ had $P$ carinii pneumonia at AIDS diagnosis and both were over a year of age (fig 1). Two children born in the British Isles developed $P$ carinii pneumonia after an earlier AIDS defining illness (table 1).

Of the 24 children with $P$ carinii pneumonia, who were born in the British Isles, a definitive diagnosis was made in $18(75 \%)$, based on the demonstration of pneumocystis with either silver stain or immunofluorescence with monoclonal antibodies (table 2 ); in six (25\%), the diagnosis was made on clinical and radiological grounds.

In 11 children, $P$ carinii pneumonia was the sole indicator disease at the time the child fulfilled the paediatric AIDS definition, and in 11 it occurred with other indicator diseases (table 1). These included severe failure to thrive $(n=6)$, cytomegalovirus $(n=3)$, severe failure to thrive and cytomegalovirus $(n=1)$, and severe failure to thrive with encephalopathy $(n=1)$. In three children, both cytomegalovirus and $P$ carinii pneumonia were isolated from bronchial secretions, and in one cytomegalovirus was isolated with $P$ carinii pneumonia from lung tissue at postmortem examination. Only three children, all under 4 months of age, had no manifestations of HIV infection at or before $P$ carinii pneumonia diagnosis. In the remainder other manifestations included failure to thrive (not meeting the AIDS definition), oral candida, bacterial infections, hepatosplenomegaly, and thrombocytopenia.

$\mathrm{T}$ cell subsets were measured within a month (before or after) of $P$ carinii pneumonia diagnosis in 15 children, and in all but two were less than $1500 / \mathrm{mm}^{3}$, the level below which $P$ carinii pneumonia prophylaxis is recommended in infants. ${ }^{6}$ However, of the eight children known to have HIV before $P$ carinii pneumonia diagnosis, only four had $\mathrm{CD} 4$ counts measured before the $P$ carinii pneumonia illness and in two these were below the threshold for prophylaxis. 
Table 3 Outcome of children surviving P carinii pneumonia illness

\begin{tabular}{lllll}
\hline Child & $\begin{array}{l}\text { P carinii } \\
\text { pneumonia } \\
\text { diagnosis }\end{array}$ & $\begin{array}{l}\text { Subsequent AIDS } \\
\text { indicator diseases }\end{array}$ & $\begin{array}{l}\text { Survival } \\
\text { (months) }\end{array}$ & Cause of death \\
\hline 1 & Presumptive & sFTT, CNS, cryptosporidiosis & 22 & Sepsis \\
2 & Presumptive & sFTT, CNS, lymphoma & $99^{\star}$ & - \\
3 & Definitive & $\begin{array}{l}\text { CNS, liver disease, sFTT, } \\
\text { recurrent bacterial infections }\end{array}$ & $10^{\star}$ & - \\
4 & Presumptive & CNS, bacterial infections & 50 & Sepsis \\
5 & Definitive & sFTT & $2^{\star}$ & - \\
6 & Definitive & sFTT, CNS & 4 & $\begin{array}{l}\text { Died of metabolic } \\
\text { problems secondary } \\
\text { to severe diarrhoea }\end{array}$ \\
7 & Definitive & sFTT & $13^{\star}$ & - \\
8 & Presumptive & sFTT, CNS, bacterial infections & 16 & Sepsis \\
9 & Definitive & CNS & $52^{\star}$ & - \\
\hline
\end{tabular}

$\mathrm{CNS}=\mathrm{HIV}$ encephalopathy; $\mathrm{sFTT}=$ severe failure to thrive.

${ }^{\star}$ Children still alive by 31 October 1992 .

PROPHYLAXIS AND TREATMENT

In $16(67 \%)$ of the 24 children, the diagnosis of HIV infection was made after presentation with $P$ carinii pneumonia. Only one of the eight children known to be HIV positive before the development of $P$ carinii pneumonia had received $P$ carinii pneumonia prophylaxis. This child received inhaled pentamidine and was one of the two who was diagnosed as having AIDS before developing $P$ carinii pneumonia. After $P$ carinii pneumonia diagnosis all children received treatment with high dose trimethoprim-sulphamethoxazole (TMP-SMX) which was started on the day of admission to hospital in eight children and between one and 22 days later in the remainder. Five children (all white) had allergic skin reactions to TMP-SMX; in one child this was severe with fever, rash, and raised liver transaminases. Eleven children also received pentamidine treatment after TMPSMX had commenced and 15 received steroids. All children required oxygen treatment and 14 were ventilated (see table 2). Pneumothorax developed in five children, in one before starting ventilation.

OUTCOME

All 24 children have been followed up for at least three months since $P$ carinii pneumonia. The three month survival rate was $38 \%$ (table 2). All nine children who survived

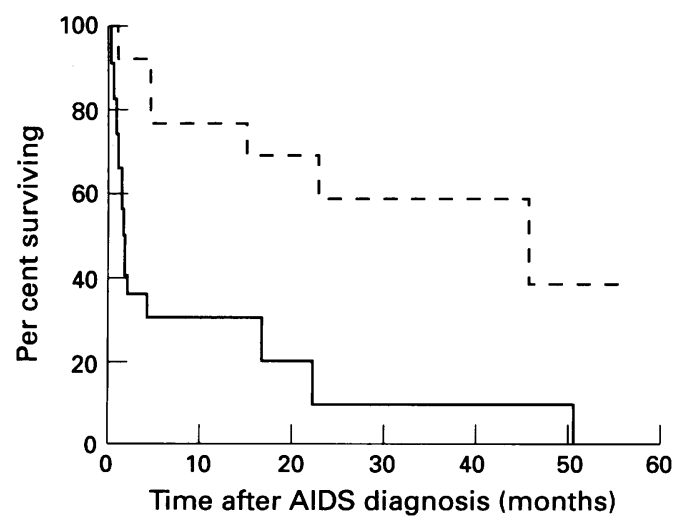

Figure 2 Survival of children born in the British Isles after first AIDS indicator disease in the first year of life; solid line indicates P carinii pneumonia as first AIDS indicator disease $(n=22)$ and dotted line other first AIDS indicator diseases $(n=12)$. (The first AIDS diagnoses in these 12 children were severe failure to thrive, lymphocytic interstitial pneumonitis, severe recurrent bacterial infections, HIV encephalopathy, and cytomegalovirus.)
$P$ carinii pneumonia subsequently developed further AIDS indicator diseases, in particular HIV encephalopathy which developed in seven (78\%) (table 3).

Figure 2 compares survival of children after $P$ carinii pneumonia with that of children developing other AIDS indicator diseases in the first year of life. Of the 34 children developing AIDS in infancy, $22(65 \%)$ had $P$ carinii pneumonia as the first AIDS indicator disease, occurring either alone or in combination. Of the 12 children who developed other AIDS indicator diseases, two subsequently developed $P$ carinii pneumonia from which one child died. Among the children who presented with $P$ carinii pneumonia as their first AIDS indicator disease and who survived the first three months, the subsequent survival pattern was similar to those who first developed other AIDS diagnoses. $P$ carinii pneumonia accounted for $14 / 17(82 \%)$ deaths occurring in the first year of life among children with vertically acquired HIV infection born in the British Isles.

\section{Discussion}

The spectrum of AIDS and clinical pattern of $P$ carinii pneumonia in children with vertically acquired HIV infection in the British Isles is similar to that reported elsewhere. ${ }^{1-478}$ Findings are similar to those in USA where $39 \%$ of children with AIDS presented with $P$ carinii pneumonia which was the most common AIDS indicator disease. ${ }^{6}$ As in other studies, 349 the outcome was poor despite availability of intensive care support and the use of specific antimicrobial treatment and steroids. All children in our series were young and two developed symptoms under 6 weeks of age. The poor prognosis may be explained, in part, by the fact that $P$ carinii pneumonia is likely to be a primary infection in young infants rather than a reactivation disease, and may be particularly severe in the presence of a damaged or immature immune system and immature lungs. In children with other congenital immunodeficiencies $P$ carinii pneumonia also occurs most often in infancy. ${ }^{10}$

In a third of children in this series, $P$ carinii pneumonia was associated with severe failure to thrive. It is difficult to determine whether severe failure to thrive was secondary to $P$ carinii pneumonia itself, or whether it was due to other HIV related manifestations, such as undiagnosed HIV encephalopathy or gastrointestinal problems. Cytomegalovirus infection was reported as a coincident AIDS indicator disease in four children with definitive $P$ carinii pneumonia, based on finding cytomegalovirus in bronchial secretions. However, as cytomegalovirus is frequently cultured from asymptomatic HIV infected children, demonstration of cytomegalovirus infected cells in histological specimens is often considered necessary to diagnosis cytomegalovirus infection. Indeed, Glaser et al observed no difference in outcome or survival from $P$ carinii pneumonia in children when cytomegalovirus was isolated from bronchoalveolar lavage fluid or lung biopsy specimens 
and not specifically treated. ${ }^{11}$ The association between $P$ carinii pneumonia and subsequent HIV encephalopathy, which was reported in $78 \%$ of children surviving $P$ carinii pneumonia in this series, has also been observed by others. ${ }^{1}$

All children in this study were treated with high dose TMP-SMX and five (all white) developed adverse reactions. Van der Ven et al have suggested that adverse reactions to TMP-SMX may be related to a genetically determined production of 'toxic metabolites'. ${ }^{12}$ There are few data on the relationship between adverse reactions to TMX-SMP and race and this could have implications for management.

Altogether $79 \%$ of the children with $P$ carinii pneumonia who required ventilation died, a figure similar to the $84 \%$ mortality reported by Vernon et al. ${ }^{4}$ The numbers in both series are small, making it difficult to identify clinical features which might characterise those children with a better chance of surviving and who might benefit from ventilation. Children were ventilated for as long as 34 days before death, and in addition to the poor outcome, this raises the question as to whether it is appropriate to ventilate children with severe $P$ carinii pneumonia and HIV at a very young age.

In this series, children had symptoms for a median of 11 days before the diagnosis of $P$ carinii pneumonia or initiation of treatment. There is a need for increased awareness of $P$ carinii pneumonia in young infants so that early treatment, which in adults with HIV infection and $P$ carinii pneumonia has been shown to improve survival, can be initiated.

The predictive value of the CD4 count, upon which recommendations for prophylaxis are based $^{6}$ is problematic. $P$ carinii pneumonia has been described in a 19 day old infant with HIV infection ${ }^{13}$ and even with frequent CD4 count measurements from birth, children at risk of $P$ carinii pneumonia may not qualify to receive prophylaxis. In this series only two of the four children who had CD4 counts measured before $P$ carinii pneumonia had CD4 counts below the threshold recommended for prophylaxis, ${ }^{6}$ and this has been reported by others. ${ }^{914}$ Where facilities for early diagnosis of HIV are available, it may be appropriate to give TMP-SMX early to all HIV infected children, with the additional advantage of helping to prevent bacterial infections. ${ }^{15}$ If early diagnosis of HIV infection or frequent follow up of the child are not possible, it may be preferable to offer $P$ carinii pneumonia prophylaxis to all children born to HIV positive mothers until HIV infection status is clarified, ${ }^{16}$ while recognising that many children would receive TMP-SMX unnecessarily, with the accompanying possibility of haematological or allergic toxicity. At present the uncertainty in this area is reflected in clinical practice. In this series, only one of eight children developing $P$ carinii pneumonia and known to be at risk had received prophylaxis. In the British Isles, of the 218 children followed up prospectively from birth, only 13 had been reported to have received prophylaxis; three of these had definitive HIV infection, two are now uninfected, and eight are of indeterminate infection status. However, some centres in the British Isles are now giving prophylaxis at 2-3 weeks of age to all children born to HIV positive women until the child is shown to be uninfected (personal communication). The risks and benefits of this and other strategies for $P$ carinii pneumonia prophylaxis require further study.

Whatever policy for primary prophylaxis is implemented, children at risk of developing $P$ carinii pneumonia require identification and intensive follow up from birth. In London, only $17 \%$ of babies born to positive women are recognised before delivery. ${ }^{5}$ Along with advice about the risks of transmitting HIV through breast feeding, prevention of $P$ carinii pneumonia is another compelling incentive for offering HIV screening in pregnancy.

\section{Addendum}

Between October 1992 and October 1993 a further 12 children born in the British Isles developed $P$ carinii pneumonia. Of these, $9 / 12(75 \%)$ did not have HIV risk ascertained before the development of $P$ carinii pneumonia.

We would like to thank the following paediatricians for so promptly and willingly completing questionnaires: A Bush, J Couriel, J Cogswell, M Gerrard, J Hammond, J Harper P Couriel, J Cogswell, M Gerrard, J Hammond, J Harper, L Stimmler, D P Heaf, K Lacey, and T Conlon. In addition, we L Stimmler, D P Heaf, K Lacey, and T Conlon. In addition, we would like to acknowledge the contribution of all paediatricians
reporting children with HIV infection through the BPSU, reporting children with HIV infection through the BPSU,
AVERT who supported this work and the collaboration of the Communicable Disease Surveillance Centre and Communicable Disease (Scotland) Unit. We would also like to thank Dr A E Ades and Professor C Peckham for their advice and comments on the manuscript.

1 Blanche S, Tardieu M, Duliege A, et al. Longitudinal study of 94 symptomatic infants with perinatally acquired human immunodeficiency virus infection. $A m \ngtr \mathrm{Dis} C$ hild 1990; 144: 1210-5.

2 Scott GB, Hutto C, Makuch RW, et al. Survival in children with perinatally acquired human immunodeficiency virus type 1 infection. N Engl f Med 1989; 321: 1791-6.

3 Connor E, Bagarazzi M, McSherry G, et al. Clinical and laboratory correlates of Pneumocystis carinii pneumonia in children infected with HIV. $\mathscr{F} A M A$ 1991; 265: 1693-7.

4 Vernon DD, Holzman BH, Lewis P, et al. Respiratory failure in children with acquired immunodeficiency syndrome and acquired immunodeficiency syndromerelated complex. Pediatrics 1988; 82: 223-8.

5 Ades AE, Davison CF, Holland FJ, et al. Vertically transmitted HIV infection in the British Isles. BMF 1993; 306: 1296-9.

6 Centers for Disease Control. Guidelines for prophylaxis against Pneumocystis carinii pneumonia for children infected with human immunodeficiency virus. $\mathscr{F} A M A$ 1991; 265: 1637-44.

7 Thomas P, Singh T, Williams R, Blum S. Trends in survival for children reported with maternally transmitted acquired immunodeficiency syndrome in New York City, 1982 to 1989 . Pediatr Infect Dis $\mathcal{7} 1992 ; 11: 34-9$.

8 Tovo PA, Martino M, Gabiano C, et al. Prognostic factors and survival in children with perinatal HIV-1 infection Lancet 1992; 339: 1249-53.

9 Bernstein LJ, Bye MR, Rubinstein AR. Prognostic factors and life expectancy in children with acquired immunodeficiency syndrome and Pneumocystis carinii pneumonia. Am $\mathcal{F}$ Dis Child 1989; 143: 775-8.

10 Walzer PD, Perl DP, Krogstad DJ, et al. Pneumocystis carinii pneumonitis and primary immune deficiency diseases of infancy and childhood. $\mathcal{f}$ Pediatr 1873; 82: 416 .

11 Glaser JH, Schuval S, Burstein O, Bye MR. Cytomegalovirus and Pneumocystis carinii pneumonia in children with acquired immunodeficiency syndrome. in children with acquired im

12 Van der Ven AJAM, Koopmans P, et al. Adverse reactions to co-trimoxazole in HIV infection [Letter]. Lancet 1991; 338: 431 .

13 Beach RS, Garcia ER, Sosa R, Good RA. Pneumocystis carinii pneumonia in a human immunodeficiency virus 1 -infected neonate with meconium aspiration. Pediatr Inf Dis F 1991; 10: 953-4.

14 Leibovitz E, Rigaud M, Pollack H, et al. Pneumocystis carinii pneumonia in infants infected with the human mmunodeficiency virus with more than $450 \mathrm{CD} 4 \mathrm{~T}$-lymphocytes per cubic millilitre. $N$ Engl $f$ Med 1990; 323: 531-3.

15 Hughes WT. Pneumocystis carinii pneumonia: new approaches to diagnosis, treatment and prevention. Pediatr Infect Dis $\mathcal{F} 1991$; 10: 391-9.

16 Allen UD, Read SE. Pneumocystis carinii pneumonia (PCP) prophylaxis for HIV infected infants: a decision analysis. Abstracts of the 1991 Interscience Conference on Antimicrobial Agents and Chemotherapy, 1991: abst 627. 